\title{
Digital Wellness Services for Young Elderly- a Missed Opportunity for Mobile Services
}

\author{
Christer Carlsson ${ }^{1}$ and Pirkko Walden ${ }^{2}$ \\ 1,2 Åbo Akademi University, Institute for Advanced Management Systems Research, Turku, Finland \\ ${ }^{1}$ christer.carlsson@abo.fi, ${ }^{2}$ pirkko.walden@abo.fi
}

Received 24 January 2016; received in revised form 7 May 2016; accepted 1 June 2016

\begin{abstract}
The ageing population of Europe is a concern for political decision makers and visions on how to deal with the issues are being debated. The issues raised concern elderly people, the age group 75-90 years, but not much thought is given the young elderly- the age groups 60-75 years-as the serious age-related problems are not visible among them. Nevertheless, pro-active preventive action programs among the young elderly could significantly reduce the problems society faces when people become elderly. We will address the issues with the ageing population from the perspective of digital wellness services that are designed, produced and offered over omnivore platforms on smart mobile phones and backed up by analytics tools over cloud services. The aim is to keep the young elderly healthy, active and independent when they reach the $75+$ age group. In this research the digital wellness services are proposed as effective interventions to build wellness routines. The design of wellness services need to be done through co-creation with the young elderly, not for them.
\end{abstract}

Keywords: Ageing population, Digital business, Digital services, Wellness, Young elderly, Cocreation 


\section{Background and Introduction}

Europe is facing the challenges of an ageing population, which is experienced in different ways in different EU member countries and is met with different types of action programs. A common denominator seems to be that ambitious structural changes are outlined to meet the challenges, often in visionary and elegant strategic plans and political programs (see for instance, the H2020 visions) that appear to be well-intended but not well-founded in terms of facts; they are also hard to develop into realistic action programs. The approaches we discuss in Finland are not much different; they appear to be mostly focused on some isolated problems or the needs of some specific group as there happens to be some technology available that could be tried out and some influential group takes a fancy to that technology-after a while not much has happened and the results remain at the pilot stage.

We will address the issues with the ageing population from the perspective of digital wellness services that are designed, produced and offered over omnivore platforms with the aim to keep the young elderly healthy, active and independent when they reach the 75+ age group.

Research work on mobile services (see [7] for a summary) shows that with mobile technology there are good possibilities to build and implement action programs for mobile services, that (i) will have an impact on daily routines for individual citizens, that (ii) will spread and grow to groups of citizens, then (iii) will become a movement engaging hundreds of thousands of people in a country, and (iv) will move into first several, then many countries, to finally (v) become a global movement. If we apply this scenario to digital wellness services -and elderly people adopt the services and turn them into wellness routines- then this will have, through sheer numbers, an impact on health and social care costs for the ageing population. If the wellness programs touch a few million people of the ageing population, the impact on the annual EU health and social care costs will be on the scale of tens of billions of Euro.

The ageing population of Europe is a broad and ill-defined segment of the population. The issues appear to be deteriorating health conditions among the 75+ aged citizens and how a modern society should cope with them, i.e. the aim and the vision is to neutralize and/or compensate for the effects of deteriorating health. The reality is that this needs to be carried out with cost-effective, tax-funded programs. As the proportion of ageing citizens is growing in most EU countries-relatively seen fastest in Germany, Finland and Italy- there is growing political pressure to find trade-offs between the costs of the care programs and their substance as the tax-paying part of the population may not be able to afford the programs from the year 2030 onwards [25].

Thus we need to find another way. The first step is to focus on pro-active prevention, i.e. to find measures that will reduce the growth in the numbers of $75+$ aged citizens that will need the health and social care support of the society; proactive prevention puts focus on the age group young elderly-the age group 60-75 years- and develops programs that will keep them healthy, active and independent when they reach the 75+ age group. In the second step we need to develop tools that can be used for intervention-applications for mobile smartphones are now becoming and will be general purpose instruments by 2020 (the mobile connection subscriptions are more than $100 \%$ of the population in most EU countries; the proportion of smart phones have passed $60 \%$ in most EU countries; approximately $60 \%$ of the phones sold in 2015 in the EU countries were smart phones; thus most of the phones in use by 2020 will be smart phones). There is a growing market for digital health technology that we are aware of but that we are not going to address as it is out of the scope of this paper; the approach is to collect data, either from medical databases or from individual users and then to offer health advice, which is strongly regulated. Our intervention builds on collecting data on daily routines that have been shown to promote wellness and to present summary data to users that will encourage them to expand and improve on their routines. The third step should develop ecosystems that will maintain and further develop ICT-based tools to support the programs for the young elderly (see [17] for a similar approach); we have learned that there needs to be a commercial ecosystem to drive the maintenance and further development of sustainable digital wellness services- research projects are not enough, the services will not be sustained unless they are commercially viable. In our overall vision, the wellness services need to be produced, distributed and used for several years before we can start to follow (and measure) impacts on the young elderly age group and study changed/improved levels of health, activity and independence.

This three-step approach requires, of course, political commitment and social consensus in each EU country, but blueprints of alternative ways to build the programs can and should be worked out with research programs.

Given this outline we will add a few more elements of substance to the context description. The young elderly age group represents $18-23 \%$ of the population in most EU countries [25]. It is a large segment of the population that according to recent statistical estimates will be about 97 million EU citizens by 2020. The age interval [60-75] is, of course, not cast in concrete, the effects of age are individual and the ageing process is different for different individuals, in different cultures and in different countries. However, most people retire from working life around the age 60 and studies show that this change has an effect on their future health scenarios; other studies show that the daily routines of the young elderly have effects on the health scenarios for the 75+ age group [13].

Functional impairment covers cognitive, physical, social and emotional impairment [9]. Our work with young elderly groups in a research program called BeWell [5] has shown that functional impairment is (i) multi-dimensional, (ii) 
compensatory and (iii) non-static. Physical impairment is an unnecessarily narrow focus as there are many more aspects to the well-being of the young elderly, and most (or all) of them have impacts on the future need for health and social care. On an individual level it is probably fair to say that wellness is subjective and that the motivation for physical exercise may not be high as it has not been part of daily routines for most of an individual's adult life; on the other hand, intellectual exercises may be part of daily routines and contribute to individual overall wellness; then physical and intellectual wellness may be compensatory (and we will not make any judgement on what is a proper balance). Functional impairment is non-static; i.e., it is a dynamic process that changes in its multiple dimensionssome parts being mutually supportive, some parts being compensatory- and the dynamics has some relations to the daily routines of the young elderly [9].

The choice of wellness is motivated by the fact that wellness services will not be dependent on health or social care data that is strictly regulated in most EU countries, with country-wise differences, and with confidentiality and privacy limitations.

If digital wellness services become interventions in the daily routines of young elderly they will support the forming of daily wellness routines. Over time-the building and adoption of new wellness routines will take time [26] - this will have a measurable impact on the health and social care costs. In common sense terms- if in Finland more than 50\% of 1200000 young elderly citizens will have better health for 10 years or more, the effects on health and social care costs should be several $\mathrm{B} €$ annually.

We are running a research program called BeWell in Finland 2014-16 that is part of one of the Strategic Centres for Science, Technology and Innovation and aims at developing digital wellness services as interventions to build and sustain wellness routines among the young elderly. The BeWell has Tieto Group (a Finnish multi-national IT service company with annual revenue of $1.5 \mathrm{~B} €$ ) as the driver company and includes 10 more companies and 4 research partners. In BeWell the wellness routines are assumed to work out in the following way: (i) young elderly will develop individual daily wellness routines supported by wellness services on an omnivore platform over mobile smartphones; (ii) the wellness routines will be tailored by/for the users from 100+ smartphone applications; (iii) cloud services will support the wellness routines and collect and analyse user data for further and continuous development of wellness services. If the program will shape up in this way remains to be seen; the details on the technology are worked out in section 4.

Our interest in digital services for young elderly was triggered by the reactions from service developers and providers when we asked them why there were no mobile services developed for the young elderly [7]: they give us the wrong image, it will take too much effort to develop services in such a way that elderly people can use them and for what purpose would the elderly use mobile services?. As the young elderly represent up to $23 \%$ of the consumer market in most EU countries it appears that some strategic mistakes were made. Studies of the use of mobile phones and services among the older adults start to appear [11], [12]. Several studies in the UK [12] show that older adults (over 50 years of age) use mobile phones significantly less than younger people; the older adults use them for maintaining and developing social relationships and for health and security services. Studies show that older adults are passive users-using mobile phones when there are no alternatives; there is a general lack of understanding of the functional impairment experienced by older mobile phone users (displays too small and difficult to see, buttons and characters too small causing errors, too many functions to keep track of), older adults fear the addictive effect that is claimed to be manifest in the younger generation [12]. In a similar study in Germany [11] the research design called for a sample of mobile app users in three age groups: youngsters [- 25 years], middle agers [26-49] and best agers [50 + years]; they found significant differences between the age groups with an Unified Theory of Acceptance and Use of Technology (UTAUT)-like model: (i) convenience has a strong effect on perceived usefulness among the youngsters, has less effect among the middle agers but slightly stronger effect among the best agers; (ii) for the older groups convenience is not important for enjoyment, but it is for the youngsters; (iii) perceived ease of use has significant influence on enjoyment and intention to use among the middle agers and best agers; (iv) for middle agers enjoyment is significantly influenced by the perceived quality of a mobile app and perceived ease of use; (v) enjoyment is most important for middle agers and moderately important for best agers.

In this paper we will test the visions we have of a forgotten, very large and potentially very important market for digital wellness services with some of the hard reality of actually designing, building, launching and sustaining the use of digital wellness services [21], [22]. We need answers to some key research questions: (1) will young elderly be a relevant user group for digital wellness services, (2) do young elderly find wellness issues important, (3) can digital wellness services form wellness routines and what should be the service design and (4) what environment can sustain wellness routines for the young elderly?

After this sketch of the context and rough storyline of how digital wellness services for the young elderly are motivated and how they could become reality, we will develop the storyline with more facts and constructs in the next sections. Section 2 is a brief overview of digital business and digital wellness services, section 3 is an overview of young elderly, section 4 works out key elements of digital wellness services, section 5 presents technology platforms for digital wellness services, section 6 reports first results of the work with young elderly user groups and section 7 , finally, summarizes and makes some conclusions. We are finding answers to our four research questions but we do not yet claim to have any complete model (or theory) for the building of digital wellness services for the young elderly. 


\section{Digital Business in 2015}

The digital business is simply defined as the transformation of key business processes through the use of internet technologies [8]. The definition suggests that a simple approach with simple means will be sufficient, but practice has shown that the innovations and implementation work needed to build new business with new technology is extremely demanding. For the moment we will not get into that, but build on the understanding that we will have to transform business processes to the needs of digital wellness services if we want them to offer viable platforms for very large groups of young elderly users.

Digital wellness services for the young elderly [5] has the potential to become a disruptive intervention in the common wisdom on how to tackle the problems with an ageing population: it will be a pro-active, preventive program, it will promote wellness routines and change daily routines, it will improve health scenarios for elderly people and reduce public health and social care costs. It may help rewrite the whole context as Wikipedia changed the encyclopaedia industry, as Skype introduced peer-to-peer Internet telephony and the Voice over Internet Protocol with a disruptive impact on international telephony, and Facebook created new standards for social networks and social group interaction It will have a significant impact because the number of people involved will be very large.

The mobile technology has become an increasingly important part of digital business and is now starting to be a dominant technology in some of the developed markets. The original notion was that mobile commerce was simply understood as electronic commerce carried out over mobile phones, which was not a very successful notion in the early 2000s [7]. The breakthrough came with the mobile apps that introduced new ways for users of mobile phones to download and use digital services that required none of the professional skills needed to search for and operate internet-based services. The first apps were not very effective, nor user-friendly, but the advances in smart mobile phones have offered better and better platforms for more advanced, multi-functional and user-supportive applications.

As a benchmark we have the illustration - Figure 1, which shows that the use of digital media over smart mobile phones now has passed the use over desktops and laptops in the US market and is dominating the use of digital media. The trends are similar in the developed EU and Asian markets and from that follows that it makes sense to aim for digital business solutions to be worked out with smart mobile phones as the user platforms. We have also found out that smart mobile phones are used by a majority of the young elderly, which supports the choice to offer digital wellness services over this platform.

Internet Usage (Engagement) Growth Solid

$+11 \%$ Y $Y$ = Mobile @ 3 Hours $/$ Day per User vs. <1 Five Years Ago, USA

Time Spent per Adult User per Day with Digital Media, USA, 2008 - 2015YTD

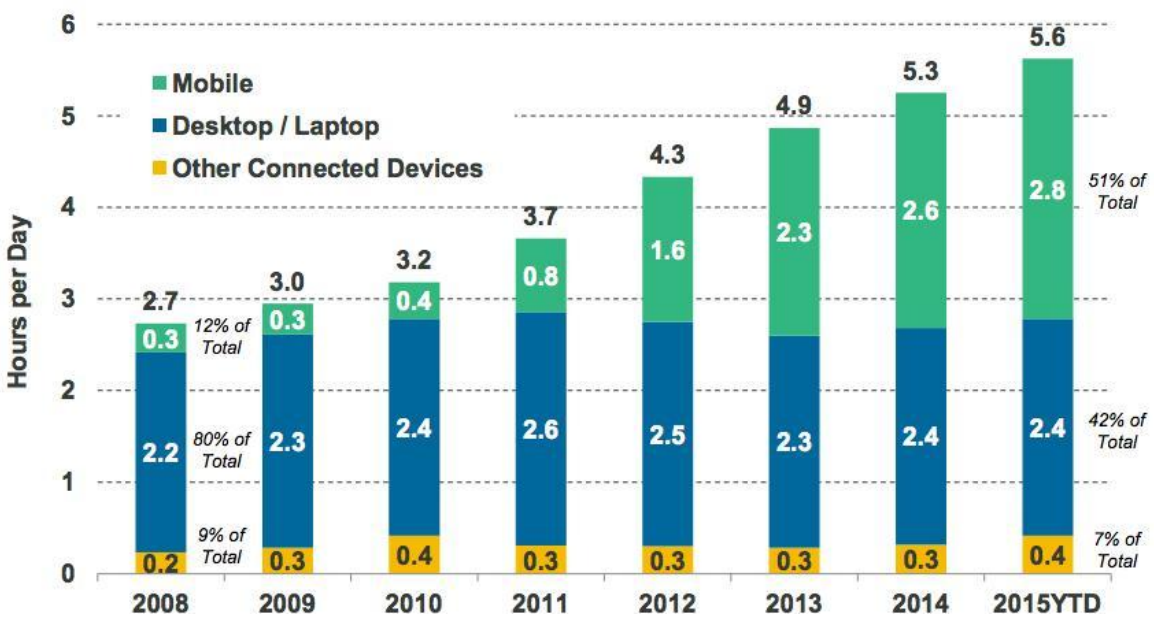

Figure 1: Mobile internet trends 2015 [8]

The digital transition of business has created a number of surprises for the business world. It is said that the digital transition is: (i) inevitable, (ii) irreversible, (iii) tremendously fast, but (iv) uncertain in execution (Helmut Krcmar in keynote to the $24^{\text {th }}$ International Conference on Information Systems Development (ISD2015 Harbin). Digital business will take over as it is both more effective and efficient than standard business practice, more productive (more products and services with less production time), more cost-effective and more profitable (more value produced with less production time) and-consequently- offers much higher return on capital invested. We did not 
actually expect the transition to be as fast as it has been and many well-established, old and successful corporations in traditional industries were taken by surprise [8]. Digital business is opening markets for innovative solutions to digital services, business models and ecosystems. This is where digital wellness services for young elderly should/will be heading-aiming for winning (mobile) platforms, using innovative business models and creating ecosystems of companies with high levels of productivity and cost effective operations. This is a first answer to question 4-the digital business provides the tools and the environment for building sustainable digital wellness services, which will be a prerequisite for sustainable wellness routines for the young elderly.

\section{Young Elderly - Part of the Ageing Population}

For the young elderly age group the society needs to have a strategy with priorities which are-and need to bedifferent from the strategy and priorities for the old people. Programs for the ageing population appear to focus on the senior $[75+]$ and the elderly $[85+]$, at which stage the focus needs to be on care to deal with functional impairment and chronic illnesses. These are stages that we propose can be avoided with pro-active preventive wellness services for the young elderly.

A majority of the young elderly are healthy, active and socially interactive and do not require much intervention or support from the health and social care systems; for a minority of the group we could claim that health, activity and social interaction are not so good. These classifications are deliberately vague because they change from country to country, and the interpretations of them differ between countries and cultures, there are different social value systems in different countries. The young elderly (+ elderly) are a large age group in Finland, and according to the forecasts it will be about $22 \%$ of the population by 2020 (table 1 ).

From the simple fact of numbers it can be seen that the Finnish society faces some challenges in terms of health and social care if more than 1.2 million citizens need care when they get older. The cost of health care for the ageing population in Finland was $3.8 \mathrm{~B} €$ in 2014; as a rule of thumb it is said that a Finnish citizen spends $80 \%$ of the health care costs (s)he spends during a lifetime during the last 10 years of his/her life. Thus much can be gained if the young elderly build up good wellness routines and stay active and healthy with them also as seniors and elderly.

Finland, Germany and Italy have the least favourable age pyramids among the EU countries, which mean that the challenges with the ageing population will first become obvious in these countries. Seen from the perspective of potential for digital wellness services and supporting technology the EU countries represent a large and growing market; the estimate is that the young elderly will be 97 million in EU by 2020 [26]. Then we have a second answer to question 4- the impact being formed by the ageing population will make it a necessity to build and sustain wellness routines.

Table 1: The proportions of the ageing population in Finland by decade [23]

\begin{tabular}{|l|l|l|l|l|l|l|l|}
\hline Year & Population & $0-14$ & $15-64$ & $65-$ & $0-14 \%$ & $15-64 \%$ & $65-\%$ \\
\hline 1900 & 2655900 & 930900 & 1583300 & 141700 & 35,1 & 59,6 & 5,3 \\
\hline 1910 & 2943400 & 1049400 & 1724500 & 169500 & 35,7 & 58,6 & 5,8 \\
\hline 1920 & 3147600 & 1051000 & 1908300 & 188300 & 33,4 & 60,6 & 6,0 \\
\hline 1930 & 3462700 & 1018300 & 2227200 & 217200 & 29,4 & 64,3 & 6,3 \\
\hline 1940 & 3695617 & 995599 & 2464107 & 235911 & 26,9 & 66,7 & 6,4 \\
\hline 1950 & 4029803 & 1208799 & 2554354 & 266650 & 30,0 & 63,4 & 6,6 \\
\hline 1960 & 4446222 & 1340187 & 2778234 & 327801 & 30,1 & 62,5 & 7,4 \\
\hline 1970 & 4598336 & 1118550 & 3052298 & 427488 & 24,3 & 66,4 & 9,3 \\
\hline 1980 & 4787778 & 965209 & 3245187 & 577382 & 20,2 & 67,8 & 12,1 \\
\hline 1990 & 4998478 & 964203 & 3361310 & 672965 & 19,3 & 67,2 & 13,5 \\
\hline 2000 & 5181115 & 936333 & 3467584 & 777198 & 18,1 & 66,9 & 15,0 \\
\hline 2010 & 5375276 & 887677 & 3546558 & 941041 & 16,5 & 66,0 & 17,5 \\
\hline 2020 & $\mathbf{5 6 3 1 0 1 7}$ & 932596 & $\mathbf{3 4 2 5} 603$ & $\mathbf{1 2 7 2 8 1 8}$ & $\mathbf{1 6 , 6}$ & $\mathbf{6 0 , 8}$ & $\mathbf{2 2 , 6}$ \\
\hline 2030 & 5847678 & 936712 & 3415342 & 1495624 & 16,0 & 58,4 & 25,6 \\
\hline 2040 & 5984898 & 923027 & 3495360 & 1566511 & 15,4 & 58,4 & 26,2 \\
\hline 2050 & 6095858 & 940800 & 3515618 & 1639440 & 15,4 & 57,7 & 26,9 \\
\hline 2060 & 6227635 & 948631 & 3523775 & 1755229 & 15,2 & 56,6 & 28,2 \\
\hline
\end{tabular}




\section{Digital Wellness Services}

The WHO defines health as "a state of complete physical, mental and social well-being and not merely the absence of disease or infirmity" [27]. When it comes to wellness there is no universally accepted definition. Wellness can be defined as a proactive and preventative approach that is designed to provide optimum levels of health, emotional and social functioning [30]. It is also stressed that wellness emphasizes the whole individual and that it is the integration of the spirit, body and the mind; and the understanding that everything we do, feel, think and believe has a direct impact on our state of health [30]. The notion of a proactive and a preventive approach is important when we discuss wellness.

There has also been quite some debate over the years about the dimensions of wellness; one of the most complete lists includes: (i) emotional, (ii) financial, (iii) occupational, (iv) environmental, (v) intellectual, (vi) physical, (vii) social and (viii) spiritual wellness [1], [16], [18], [19], [24]

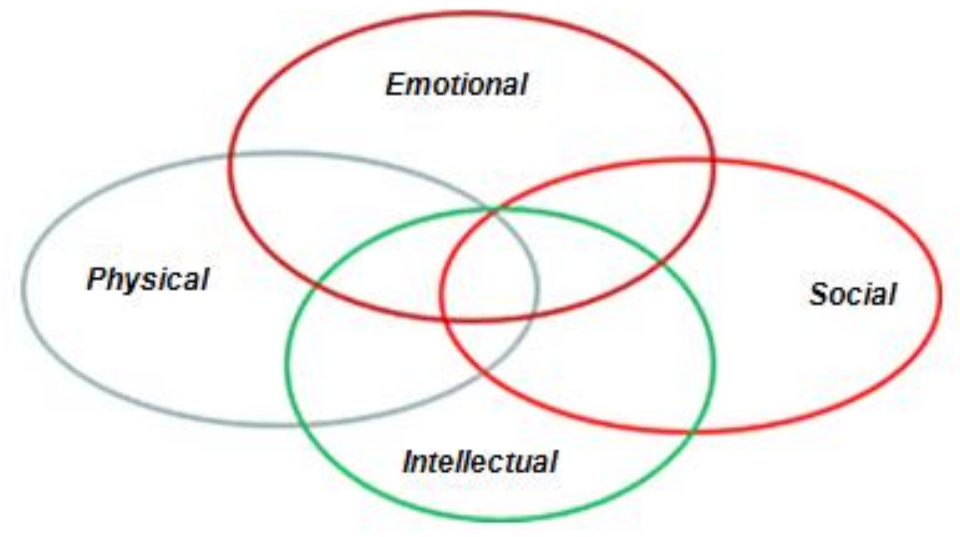

Figure 2: Four dimensions of wellness

There are some benefits in operating with wellness in a four dimension construct (figure 2): (i) intellectual wellness, (ii) physical wellness, (iii) social wellness, and (iv) emotional wellness, which mirror functional impairment dimensions. In our work with young elderly groups we have learned a few things about wellness. Even if it is accepted that building physical wellness is beneficial there is assumed to be a reasonable level which does not require daily exhortations. It is reasoned that an overall wellness can be maximized by compensating some missing level of physical wellness with improved intellectual wellness, or with improved social wellness, or with improved emotional wellness or with any combination of these. It will of course be a challenge to find some good trade-off, mapping relations between the wellness dimensions, and then to create digital wellness services to support and sustain them.

In several studies of mobile services (for a summary see [7]) we have found fault with the traditional service design for some intended potential users, who then are expected to learn how to get the service, how to get it started and then how to adapt their own routines to make use of the service. Digital wellness services for young elderly need to follow a different roadmap as we have found out that the young elderly are unwilling to spend time to adapt to requirements they do not find meaningful (this was also found in [11]). The wellness services need to be designed with the users, not for the users. The methodology for that is multi-disciplinary action design research (ADR) which is now gaining support as a key methodology in information systems research [20]. With the ADR we work with multiple, sizeable groups of wellness service users, both to identify necessary design variations and to collect the data on the forming of wellness routines. In workshops and field experiments we try to show that new, enhanced and regular wellness routines (interventions) will reduce the risk for advancing (physical, cognitive, social, emotional) impairment. In work with service developers and providers we build models to show that investment in digital wellness services will have high return on investment for (i) the service providers and technology developers in an ecosystem, (ii) for associations of the young elderly, (iii) for society, and (iv) for the individual young elderly themselves; the return is probably not measured in monetary terms (cf. [6] for linguistic measures).

The design of digital wellness services works with data that is multi-dimensional and covers the four wellness aspects. Part of the data needs to be in real time; part of it can be daily and weekly summaries and some of the data could be imported through interfaces with data sets (or databases) that have been collected for various purposes. In our work with young elderly user groups it was proposed that results from the use of digital wellness services should be used to update user profiles in health care systems (makes sense, a personal physician could get access to wellness data). All of it should be summarized and offered in an understandable-most probably tailorable- form for young elderly users over smart mobile phones (operating in Android, iOS and Windows to make sure that the services are not monopolized as they become wanted and successful in large user groups). These requirements are our present understanding of how the digital wellness services should be made operational. 


\section{Enhanced Digital Wellness Services}

A digital wellness services program for the young elderly in the context outlined in this paper can be expected to quickly get hundreds of users (in Finland, the BeWell program is backed up by two major associations of the elderly with a total membership of more than 100000 members), soon turning into thousands of users and then scaling up to tens or hundreds of thousands of users in a fairly short time. The technology infrastructure needs to be planned for very large groups of users; technology developers and providers clearly want the user groups to grow to millions of users in all EU countries.

The first choice to be made is to either work with modular platforms built from existing components or to design and build the platforms from unique, original constructs; the ADR approach [20] to the development of digital wellness services builds on (i) service co-creation [10] with the users in semi-structured workshops, (ii) flexible, adaptive designs that adapt to changing needs and requirements, (iii) new designs that adapt to and make use of technology innovations, and (iv) flexible, adaptive infrastructures that adapt to changing contexts. The ADR approach favours quick piloting and prototyping which is easier to carry out with platforms that are composed of existing components. We use the Wellmo omnivore platform and the Tieto cloud service platform as development environments.

Wellmo is called an omnivore platform (eats everything) because it interacts with 100+ digital devices and applications, which is useful for building a large set of wellness services and adapting them to user needs; the Wellmo was first developed by Nokia and then turned into a spin-off that was launched in the business-to-business market as a basis for corporate wellness programs offered to employees (figure 3 presents an overview of the features). The links (figure 4) cover most of the key fitness brands and devices.

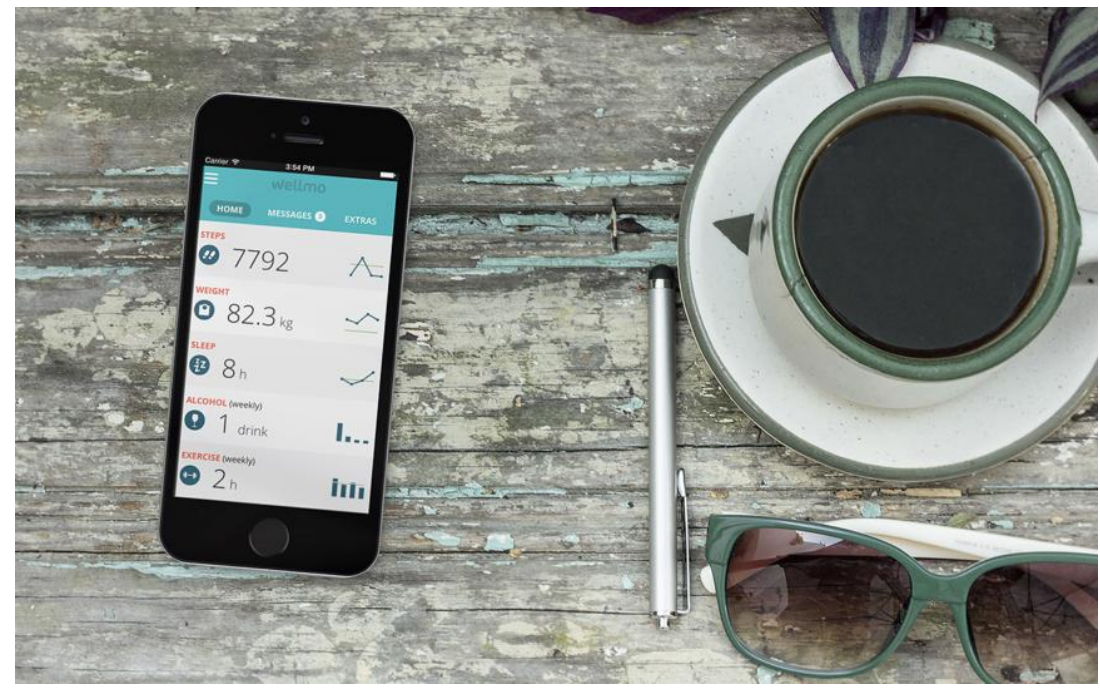

Figure 3: The Wellmo platform

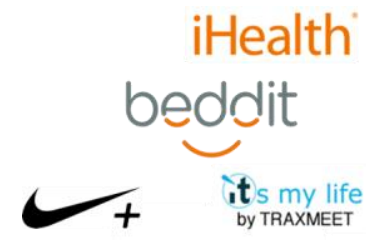

JAWBONE

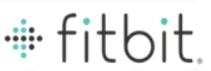

STRAVA Runkeeper

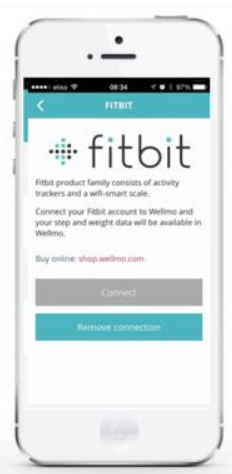

PดEAR.

\section{Withings} ETIFIT

Orodymedí

GARMIN

mapmy\&fitness
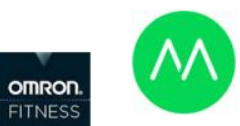

Figure 4: Wellmo connected devices and applications (selection) 
The Wellmo (figure 3) operates as an application on a smart phone with back-up support over the Wellmo website and keeps track of (i) the number of steps per day (recorded through the smart phone or a fitness wearable), (ii) the sleep and sleep patterns (recorded by a fitness wearable), (iii) the exercises per day (several different forms can be specified and activity recorded by a fitness wearable or fed manually), (iv) weight (recorded by digital scales and sent by Bluetooth or fed manually), and ( $v$ ) drinking and smoking habits (fed manually). For each activity the user can define daily or weekly targets and will get weekly and monthly updates on wellness activities; the Wellmo results can be shared over social media, peer groups can be organised and friends can keep encouraging each other. Part of the BeWell program is working with new features adapted to the needs of young elderly to be added to the Wellmo which then will be evaluated, tested and validated by user groups.

The Wellmo platform has gone through several development cycles and its functionality has been extensively tested; it is in active use by more than 40 corporations in half a dozen countries. In the step from the corporate to the young elderly market the omnivore platform is developed with a focus on usability to meet the needs of the ageing population (this has not always been recognized as important, see [12] for data from the UK). The tracker and the connected device portfolio are expanded to cover devices and applications used on the intellectual wellness side; the API is enhanced to support real time linking to external functions on top of the Tieto platform and the scalability is enhanced to cope with very large user groups.

A quick study of the supply of digital fitness devices-also said to be ubiquitous as they should be worn at all timesshows that there are a number of standard features offered by most devices. There are sensors that follow steps, sleep, heart rate and functions to offer smart alarms and incoming call, message and email alerts. The fitness devices communicate with smart mobile phones and tablets over Bluetooth and have back-up support through websites managed by the device developers and vendors. The fitness devices are designed for active (or at least semi-active) athletes and fitness enthusiasts; they are not built for the young elderly and it turned out that only part of the functions could be adapted to the wellness routines of the 60-75 age group. The leading brands are Fitbit, Garmin, Jawbone, Misfit, Polar and Sports Tracker (the market positions change quite often) and they are priced in the $49.90 €-249.90 €$ range; the important difference between the fitness bracelets appears to be in the software and the data produced that can be used for wellness modelling and analysis. A digital wellness service program should produce a generic set of services (that can be updated, maintained and developed in some easily coordinated way), which is why we decided to work on an omnivore platform that can import data from all possible fitness devices through interface solutions that are made possible with advanced, innovative software architecture. It should be mentioned that there are advanced smart watches introduced by Apple, Garmin, Samsung, etc. that also offer fitness data but appear to be aimed for the digital health care market; then there is the Chinese Xiaomi Mi Band that sells at USD 14.99 through Amazon but offers most of the functionality of the higher priced fitness devices, which shows that the fitness devices probably will be offered at much lower prices in the near future.

The back-end infrastructure builds on the Tieto cloud services platform [3] for advanced analytics which supports the design, implementation, monitoring, verification and validation of the digital wellness services (figure 5). The platform offers a full stack portfolio for different types of digital wellness services combined with a cloud laas to support modern services such as automated adaptive coaching and advanced analytics.

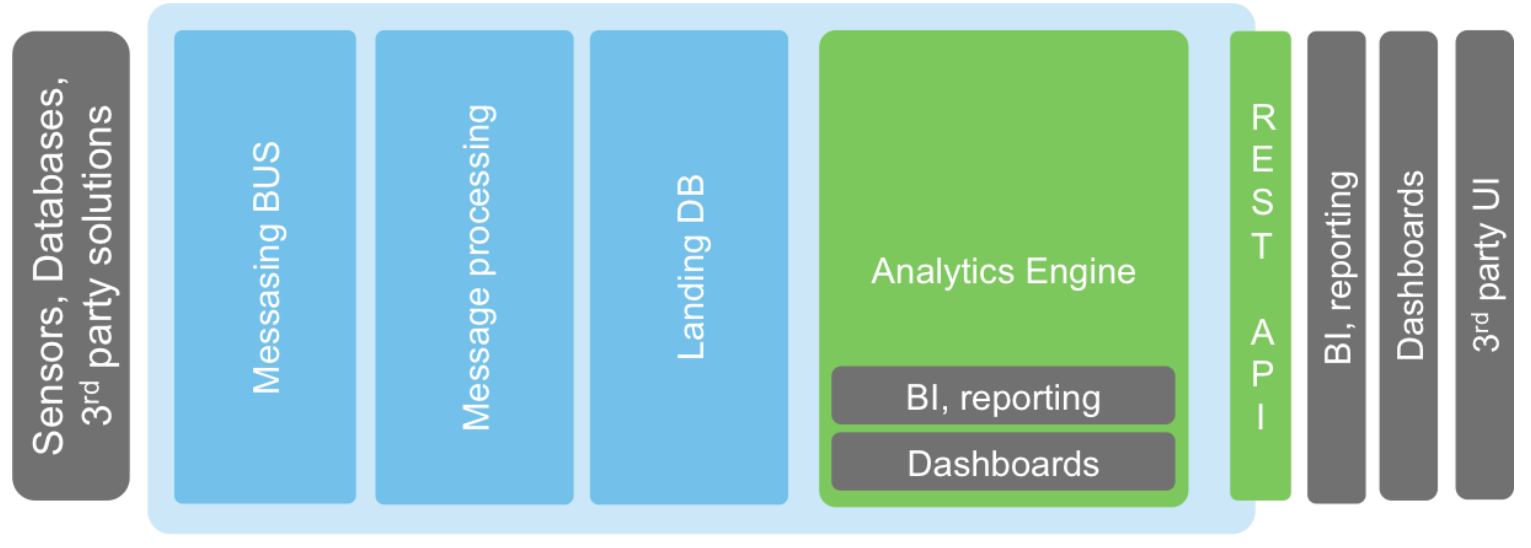

Figure 5: Tieto cloud service platform for advanced analytics

The Wellmo support website can easily handle interactions with hundreds of users but as we scale up to first thousands, then tens of thousands and moving on to hundreds of thousands of users for which we want to process data in (near) real time we are going to need the Tieto cloud service platform (figure 5), that can work with input of sensor data from fitness devices, smart mobile phones, digital health devices, etc., with data from all types of databases and from third party software systems and can produce reports for dashboards on smart mobile phones (that can be, for instance, a Wellmo format), reports for smart watches, tablets or laptops, etc.

Advanced analytics tools that will work in an environment of heterogeneous and not well structured data sources [6] are needed to build data fusion [29] with further extensions to information and knowledge fusion [28]. The fusion is a 
key to meaningful summaries and follow-up reports on progress of wellness routines, which can be designed to offer the advice of a coach or a personal trainer for the wellness service user. The advice is a typical value-adding service that can/will be used to build commercial solutions for the digital wellness services. This will be advanced technology-we should, by the way, get away from the common wisdom that elderly people do not need advanced technology; we have a 100 million consumer market in the EU.

The summaries and follow-up reports should be produced in forms that are adaptive to the users' contexts [6], to the data collected with various sensor systems, to various types of apps and to the cognitive profiles of the users. This sounds reasonable but requires advanced and innovative designs [4]. With the material from sections 4 and 5 we can offer some answers to question 3: The design of digital wellness services should be done with the users, not for the users; the ADR offers a reasonable basis for interactive design work with the young elderly; the technology framework should provide data, information and knowledge as support for the adoption of wellness services; the user interface should be an omnivore platform to allow users to compose services that can sustain wellness routines.

\section{Young Elderly User Groups}

We have learned that the young elderly form user groups that differ from what we have learned from the literature (see section 1) and from our own work with mobile value services [2], [7]. Thus we realized that we need to gain some understanding of how well young elderly can and will adopt mobile services and can work with mobile applications. We also need to find out about their attitudes to wellness and to get active on improving their physical wellness. Young elderly user groups have been organized and worked with us in semi-structured workshops on the design of wellness services; they are using the Wellmo platform and provide feedback on its functionality and usability; some of them use activity bracelets (connected to Wellmo over Bluetooth) and work out how they combine with the Wellmo platform; so far we have collected material and knowledge from about 100 semi-structured workshops. We learned that young elderly are experienced, not easily impressed by new technology and confident with their daily routines, i.e. building interventions to form wellness routines may have some challenges. On the other hand, there is an important difference from other user groups that we have studied-the young elderly have time to spend on what they find worthwhile, they do not have the time pressure of work life and obligations to adjust to the routines of a work environment.

We used the insight from the semi-structured workshops to organize a survey to get a first overview of the characteristics of the young elderly. We asked the association for elderly in Mariehamn (in the Åland Islands that with 28000 inhabitants is a representative snapshot of the Finnish society) to invite their young elderly to participate in a survey in the fall 2015. A letter was mailed (the association did not have emails registered for its members) to 380 members with an invitation to answer a questionnaire through a link to Webropol; we collected 101 usable answers (a $26.6 \%$ answering rate) that offers some insight into the group; the survey is now (spring 2016) followed up by indepth, semi-structured interviews with 25 young elderly.

The proportion male/female is $44.6 / 54.5 \% ; 83.1 \%$ of the respondents belong to the young elderly, and a further $14.9 \%$ are a bit older; $65.3 \%$ are married and $14.9 \%$ are widowed; $77.2 \%$ have a university or technical/commercial degree (university education is rather rare for this age group, which is why we later combined it with second level degrees), $20.8 \%$ have a basic education; $75.2 \%$ are retired and $23.8 \%$ are working full- or part-time or are carrying out voluntary work; the most typical annual incomes before tax is < $30 \mathrm{k} €(51.5 \%)$, followed by $30-40 \mathrm{k} €(19.9 \%)$, 40 $50 \mathrm{k} €(9.9 \%)$ and $>50 \mathrm{k} €(17.8 \%)$. These profiles are typical for the Åland Islands and are representative for the group of young elderly.

We plan to run the digital wellness services over smart mobile phones; the summary shows that Nokia/Lumia/Microsoft is the most used phone (46.5\%), followed by iPhone (23.3\%), Samsung (14.0\%) and Other $(12.8 \%)$; we collected data on the actual types of phones in use and found out that a majority (about $73 \%$ ) use smart mobile phones; this was confirmed with the result that $72.9 \%$ use mobile apps for navigation, weather forecasting, Internet search, etc.

The respondents answered questions about how useful, easy to use and valuable mobile apps are for them following the UTAUT2 constructs [26]. For the about 70 respondents that use mobile apps we found some useful profiles:

The adoption of mobile apps scored high on a 5-grade Likert scale:

- $\quad$ Mobile apps are useful in my daily life [4.32];

- I will continue to use mobile apps [4.19];

- $\quad$ Mobile apps help me to carry out my tasks faster [4.08];

- $\quad$ Using mobile apps helps me to carry out important tasks [3.94]; 
- I can use mobile apps without assistance [3.91];

- Have the necessary knowledge to use mobile apps [3.87];

- It is easy for me to learn to use mobile apps [3.79];

- I can use the mobile apps I need with the phone I have [3.75].

The results need to be tested with a larger sample-a study of a sample of 1800 participants is planned as the next step- but the indications are: (i) the young elderly use of smart mobile phones is sufficient to launch digital wellness services; (ii) the young elderly are confident users of mobile apps, which is a prerequisite for getting the wellness services adopted. On the other hand, the proposal-I am addicted to the use of mobile apps [2.72]- indicates that the young elderly are critical of how they spend their time with mobile apps.

All the 101 respondents answered questions relating to intellectual and physical wellness on a 6-grade forced scale and a number of proposals scored high:

- Intellectual challenges are important for my wellbeing [4.91];

- I get sufficient intellectual stimulation from my everyday life [4.61];

- My physical health has been good compared to people around me [4.38];

- My resistance to illness is good [4.24];

- The amount of information I have to process in my daily life is suitable for me (not too much, not too little) [4.20];

- I expect my physical health to remain good [4.14];

- I expect my physical health to deteriorate with increasing age [3.94].

These results are mainly indicative but show that there is at least interest in discussing wellness issues. Many regard their physical wellness to be good, which we both expected and also found out in the semi-structured workshops. An interesting aspect is that physical wellness is judged relative to others (peers, friends, family) which shows that we should consider combining physical wellness services with social media support (Fitbit, Polar, Jawbone, etc. support the forming of peer groups). Intellectual wellness is surprisingly important and we will have to find some good ways to combine intellectual and physical wellness and to figure out if these are compensatory or supplementary.

We have experimented with various methods to find out if there are sub-groups among the respondents with similar characteristics for which we could tailor some wellness features; these groups are very small in the sample of 101 respondents but will be sufficiently large to support a set of applications (with developers and distributors) when we get to work with 1.2 million potential users of the wellness services. For instance, an analysis of variance (ANOVA) was run on a number of combinations of the variables and significant differences were found on intellectual challenges are important for my wellbeing + I expect my physical health to remain good + the amount of information I have to process in my daily life is suitable for me (not too much, not too little) when the respondents were ordered on the levels of education (table 2); this group of young elderly with a positive attitude to their daily life will probably be more receptive to digital wellness services aimed at improving their wellness than those with a negative attitude to young elderly life; when working out designs of wellness services we will probably also find differences in the designs, we will find differences in the need for support, etc.

Table 2: ANOVA on pairings of intellectual wellness variables

Tests of between-subjects effects

Dependent variable: SUM wellness1

\begin{tabular}{|l|l|l|l|l|l|l|}
\hline Source & $\begin{array}{l}\text { Type III Sum } \\
\text { of Squares }\end{array}$ & df & $\begin{array}{l}\text { Mean } \\
\text { Square }\end{array}$ & F & Sig. & $\begin{array}{l}\text { Partial Eta } \\
\text { Squared }\end{array}$ \\
\hline Corrected model & $6.151^{\mathrm{a}}$ & 2 & 3.076 & 3.441 & .037 & .084 \\
Intercept & 1466.040 & 1 & 1466.040 & 1640.116 & .000 & .956 \\
Q4d & 6.151 & 2 & 3.076 & 3.441 & .037 & .084 \\
Error & 67.040 & 75 & .894 & & & \\
Total & 1566.889 & 78 & & & & \\
Corrected total & 73.191 & 77 & & & \\
\hline
\end{tabular}

${ }^{\mathrm{a}} \mathrm{R}$ Squared $=.084$ (adjusted $\mathrm{R}$ Squared $=.060$ ) 
One of the indications is that the young elderly are well aware of the intellectual wellness dimensions but we should probably find out more about the underlying factors with larger samples. Still it appears that there is support for extending wellness beyond the support for physical wellness. It is also not surprising that young elderly think about and evaluate their physical health-the response to the BeWell proposals to develop support tools for improving physical wellness has been enthusiastically supportive.

These results offer us preliminary answers to question 2: Young elderly rate the wellness issues as important; by combining the wellness proposals with the proficiency of using mobile apps we find support for the plan to build digital wellness services for mobile (omnivore) platforms. We also have confidence in the following answer to question 1: A sufficient majority of the young elderly has sufficient confidence in their skills to use mobile technology for it to be a viable proposal to promote digital wellness services as an intervention to build wellness routines.

We used Fischer's test [14], [15] to search for combinations of attitudes to mobile applications and physical and intellectual wellness (table 3).

Table 3: Fischer's test on combinations of the use of mobile applications and wellness

\begin{tabular}{|c|c|c|c|c|c|c|c|c|c|c|c|c|c|c|c|c|c|}
\hline \multicolumn{18}{|c|}{$A=0,05 I d f=1$} \\
\hline \multicolumn{3}{|c|}{ Gender } & \multicolumn{3}{|c|}{$\begin{array}{l}\text { Age } \\
<=69 \mathrm{I}>69 \text { yrs }\end{array}$} & \multicolumn{3}{|c|}{$\begin{array}{l}\text { Edu } \\
\text { folk-handel I } \\
\text { Institute-uni }\end{array}$} & \multicolumn{3}{|c|}{$\begin{array}{l}\text { Status } \\
\text { Occupational I } \\
\text { retired }\end{array}$} & \multicolumn{3}{|c|}{$\begin{array}{l}\text { Income } \\
<=30^{\prime} 000 € \mathrm{I}> \\
30^{\prime} 000 €\end{array}$} & \multicolumn{3}{|c|}{$\begin{array}{l}\text { Using apps } \\
\text { routine I advanced }\end{array}$} \\
\hline \begin{tabular}{|l|} 
Chi- \\
square I \\
Asym. \\
Sig (2- \\
sided) \\
\end{tabular} & $\begin{array}{l}\text { Fisher's } \\
(2- \\
\text { sided })\end{array}$ & $\mathrm{N}$ & \begin{tabular}{|l|} 
Chi- \\
square I \\
Asym. \\
Sig (2- \\
sided \\
\end{tabular} & \begin{tabular}{|l|} 
Fisher's \\
$(2-$ \\
sided $)$
\end{tabular} & $\mathrm{N}$ & \begin{tabular}{|l|} 
Chi- \\
square I \\
Asym. \\
Sig (2- \\
sided \\
\end{tabular} & \begin{tabular}{|l|} 
Fisher's \\
$(2-$ \\
sided $)$
\end{tabular} & $\mathrm{N}$ & \begin{tabular}{|l|} 
Chi- \\
square I \\
Asym. \\
Sig (2- \\
sided \\
\end{tabular} & $\begin{array}{l}\text { Fisher's } \\
(2- \\
\text { sided })\end{array}$ & $\mathrm{N}$ & \begin{tabular}{|l|} 
Chi- \\
square I \\
Asym. \\
Sig (2- \\
sided \\
\end{tabular} & $\begin{array}{l}\text { Fisher's } \\
(2- \\
\text { sided })\end{array}$ & $\mathrm{N}$ & \begin{tabular}{|l|} 
Chi- \\
square I \\
Asym. \\
Sig (2- \\
sided \\
\end{tabular} & $\begin{array}{l}\text { Fisher's } \\
(2- \\
\text { sided })\end{array}$ & $N$ \\
\hline $\begin{array}{l}0,247 \mid \\
0,619\end{array}$ & 0,740 & 74 & $\begin{array}{l}1,816 \mid \\
0,178\end{array}$ & 0,299 & 74 & $\begin{array}{l}8,9751 \\
0,003\end{array}$ & 0,006 & 74 & $\begin{array}{l}4,2811 \\
0,039\end{array}$ & 0,053 & 74 & $\begin{array}{l}1,850 \text { I } \\
0,174 \\
\end{array}$ & 0,308 & 74 & $\begin{array}{l}2,5861 \\
0,108\end{array}$ & 0,195 & 72 \\
\hline $\begin{array}{l}0,072 \text { I } \\
0,789\end{array}$ & 1,000 & 72 & $\begin{array}{l}2,051 । \\
0,152\end{array}$ & 0,178 & 72 & $\begin{array}{l}4,139 \text { । } \\
0,042\end{array}$ & 0,075 & 72 & $\begin{array}{l}3,0131 \\
0,083\end{array}$ & 0,124 & 71 & $\begin{array}{l}1,994 \mid \\
0,158\end{array}$ & 0,188 & 71 & 0,9921 & 0,351 & 69 \\
\hline $\begin{array}{l}1,312 \text { I } \\
0,252\end{array}$ & 0,305 & 72 & $\begin{array}{l}0,059 \mid \\
0,809\end{array}$ & 1,000 & 72 & $\begin{array}{l}1,144 \mid \\
0,285\end{array}$ & 0,393 & 72 & $\begin{array}{l}0,0501 \\
0,823\end{array}$ & 1,000 & 71 & $\begin{array}{l}3,6001 \\
0,0578\end{array}$ & 0,072 & 71 & 0,4101 & 0,550 & 69 \\
\hline $\begin{array}{l}0,021 \text { । } \\
0,884\end{array}$ & 1,000 & 72 & $\begin{array}{l}0,791 । \\
0,374\end{array}$ & 0,430 & 72 & $\begin{array}{l}1,573 \mid \\
0,210\end{array}$ & 0,252 & 72 & $\begin{array}{l}1,965 \text { I } \\
0,161\end{array}$ & 0,236 & 71 & $\begin{array}{l}0,006 \text { I } \\
0,941\end{array}$ & 1,000 & 71 & $\begin{array}{l}7,2221 \\
0,007\end{array}$ & & 69 \\
\hline $\begin{array}{l}0,3401 \\
0,560\end{array}$ & 0,598 & 67 & $\begin{array}{l}1,281 । \\
0,258\end{array}$ & 0,284 & 67 & $\begin{array}{l}2,467 \mid \\
0,116\end{array}$ & 0,140 & 67 & $\begin{array}{l}3,772 \text { I } \\
0,052\end{array}$ & 0,069 & 66 & $\begin{array}{l}0,184 \mid \\
0,668\end{array}$ & 0,787 & 66 & $\begin{array}{l}1,475 \mid \\
0,225\end{array}$ & 0,323 & 65 \\
\hline $\begin{array}{l}0,7931 \\
0373\end{array}$ & 0,465 & 73 & $\begin{array}{l}2,712 \text { I } \\
0,100\end{array}$ & 0,137 & 73 & $\begin{array}{l}1,3291 \\
0,249\end{array}$ & 0,293 & 73 & $\begin{array}{l}10,646 \\
0,001\end{array}$ & 0,001 & 72 & $\begin{array}{l}0,241 \mid \\
0,624\end{array}$ & 0,806 & 72 & $\begin{array}{l}3,896 \text { I } \\
0,048\end{array}$ & 0,087 & 70 \\
\hline $\begin{array}{l}1,134 \text { I } \\
0,287\end{array}$ & 0,334 & 73 & $\begin{array}{l}4,595 \mid \\
0,032\end{array}$ & 0,047 & 73 & $\begin{array}{l}1,329 \mid \\
0,249\end{array}$ & 0,293 & 73 & $\begin{array}{l}4,6201 \\
0,032\end{array}$ & 0,050 & 72 & $\begin{array}{l}0,963 \mid \\
0,326 \\
\end{array}$ & 0,462 & 72 & $\begin{array}{l}6,452 \mid \\
0,011\end{array}$ & & 70 \\
\hline \begin{tabular}{|l|} 
Chi- \\
square I \\
Asym. \\
Sig (2- \\
sided)
\end{tabular} & $\begin{array}{l}\text { Fisher's } \\
(2- \\
\text { sided })\end{array}$ & $\mathrm{N}$ & \begin{tabular}{|l} 
Chi- \\
square I \\
Asym. \\
Sig (2- \\
sided
\end{tabular} & $\begin{array}{l}\text { Fisher's } \\
(2- \\
\text { sided })\end{array}$ & $\mathrm{N}$ & \begin{tabular}{|l|} 
Chi- \\
square I \\
Asym. \\
Sig (2- \\
sided
\end{tabular} & $\begin{array}{l}\text { Fisher's } \\
(2- \\
\text { sided })\end{array}$ & $\mathrm{N}$ & \begin{tabular}{|l|} 
Chi- \\
square I \\
Asym. \\
Sig (2- \\
sided
\end{tabular} & $\begin{array}{l}\text { Fisher's } \\
(2- \\
\text { sided })\end{array}$ & $\mathrm{N}$ & \begin{tabular}{|l|} 
Chi- \\
square I \\
Asym. \\
Sig (2- \\
sided \\
\end{tabular} & $\begin{array}{l}\text { Fisher's } \\
(2- \\
\text { sided })\end{array}$ & $\mathrm{N}$ & $\begin{array}{l}\text { Chi- } \\
\text { square I } \\
\text { Asym. } \\
\text { Sig (2- } \\
\text { sided }\end{array}$ & $\begin{array}{l}\text { Fisher's } \\
(2- \\
\text { sided })\end{array}$ & $\mathrm{N}$ \\
\hline $\begin{array}{l}2,1431 \\
0,143\end{array}$ & 0,176 & 97 & $\begin{array}{l}3,2211 \\
0,073\end{array}$ & 0,134 & 96 & $\begin{array}{l}3,3471 \\
0,067\end{array}$ & 0,117 & 96 & $\begin{array}{l}0,9901 \\
0,320\end{array}$ & 0,444 & 97 & $\begin{array}{l}2,9501 \\
0,086\end{array}$ & 0,159 & 97 & $\begin{array}{l}0,0001 \\
1,000\end{array}$ & 1,000 & 72 \\
\hline $\begin{array}{l}0,212 \text { I } \\
0,645\end{array}$ & 0,781 & 99 & $\begin{array}{l}3,292 \text { I } \\
0,065\end{array}$ & 0,091 & 98 & $\begin{array}{l}10,839 \mid \\
0,001\end{array}$ & 0,002 & 96 & $\begin{array}{l}0,1731 \\
0,677\end{array}$ & 1,000 & 99 & $\begin{array}{l}5,743 \mid \\
0,017\end{array}$ & & 99 & $0,077 \mid$ & 1,000 & 73 \\
\hline $\begin{array}{l}3,771 \text { I } \\
0,052\end{array}$ & 0,057 & 99 & $\begin{array}{l}0,182 \text { I } \\
0,669\end{array}$ & 0,809 & 98 & $\begin{array}{l}10,832 \text { I } \\
0,001\end{array}$ & 0 & 98 & $\begin{array}{l}0,035 \text { I } \\
0,851\end{array}$ & 1,000 & 99 & $\begin{array}{l}7,513 \mid \\
0,006\end{array}$ & 0,008 & 99 & $\begin{array}{l}0,0721 \\
0,789\end{array}$ & 1,000 & 73 \\
\hline $\begin{array}{l}3,078 \text { I } \\
0,079\end{array}$ & 0,096 & 95 & $\mid \begin{array}{l}0,018 \mid \\
0,894\end{array}$ & 1,000 & 94 & $\begin{array}{l}3,238 \mid \\
0,072\end{array}$ & 0,110 & 94 & $\begin{array}{l}0,614 \text { I } \\
0,433\end{array}$ & 0,575 & 94 & $\begin{array}{l}4,171 \text { । } \\
0,041\end{array}$ & 0,055 & 94 & $|0,031|$ & 1,000 & 69 \\
\hline $\begin{array}{l}1,625 \text { I } \\
0,202\end{array}$ & 0,265 & 97 & $\begin{array}{l}0,043 \mid \\
0,836\end{array}$ & 1,000 & 96 & $\begin{array}{l}1,188 \mid \\
0,276\end{array}$ & 0,335 & 96 & $\begin{array}{l}4,086 \\
0,043\end{array}$ & 0,066 & 97 & $\begin{array}{l}0,1121 \\
0,738\end{array}$ & 0,826 & 97 & $\begin{array}{l}2237 \mid \\
0,135\end{array}$ & 0,156 & 72 \\
\hline $\begin{array}{l}0,808 \text { I } \\
0,369\end{array}$ & 0,385 & 98 & $\mid \begin{array}{l}1,971 \mid \\
0,160\end{array}$ & 0,185 & 97 & $\begin{array}{l}5,828 \mid \\
0,016\end{array}$ & 0,029 & 97 & $\begin{array}{l}2,207 \mid \\
0,137\end{array}$ & 0,195 & 98 & $\begin{array}{l}0,162 \text { I } \\
0,687\end{array}$ & 0,825 & 98 & $\begin{array}{l}0,3301 \\
0,566\end{array}$ & 0,763 & 73 \\
\hline
\end{tabular}

cursive text $=1$ (or more) cells have expected count less than 5

Fisher's = Fisher's Exact Test (Exact significance (2-sided): A test for independence in a 2x2 table: It is most useful when the total sample size and the expected values are small.

Obviously the cut-offs are somewhat arbitrary and another person might use different language:

P > 0.10: $\quad$ No evidence against the null hypothesis. The data appear to be consistent with the null hypothesis.

$\mathbf{0 . 0 5}<\mathbf{P}<\mathbf{0 . 1 0}$ : Weak evidence against the null hypothesis in favour of the alternative.

$0.01<\mathrm{P}<0.05$ : Moderate evidence against the null hypothesis in favour of the alternative.

$0.001<P<0.01$ : Strong evidence against the null hypothesis in favour of the alternative.

$\mathbf{P}<\mathbf{0 . 0 0 1}$ : Very strong evidence against the null hypothesis in favour of the alternative.

We found a number of significant combinations which offer some more insight of the attitudes of the respondents. The most visible differences were found between the two groups with different education (I think that mobile 
applications are useful in my daily life, I get sufficient intellectual stimulation from my everyday life, my physical health has been good compared to people around me, I expect my physical health to remain good) and the better educated group is positive to the use of mobile applications, experiences intellectual stimulation in the everyday life and is positive to the prospects for good physical health.

The observation it is easy for me to learn to use mobile apps shows significant differences in terms of age, status (active in full- or part-time or voluntary work vs. full-time retired) and the advanced or routine use of applications. Status also gave significant difference re the statement I have the necessary knowledge to use mobile apps.

The statement using mobile apps helps me to carry out important tasks shows significant differences re the advanced or routine use of applications, which is not unexpected.

Regarding wellness the two statements I get sufficient intellectual stimulation from my everyday life and my physical health has been good compared to people around me show significant differences between the two income groups.

We tested combinations of statements with Cronbach's alpha (a statistic used to measure internal consistency) to test if we can find similarities in attitude among the respondents and found a number of combinations; the most consistent combination of statements was (Cronbach alpha $=0.925)$ : mobile apps are useful in my daily life [0.814] and using mobile apps helps me to carry out important tasks [0.836] and mobile apps help me to carry out my tasks faster [0.773] and using mobile apps increases my productivity [0.709] and using mobile apps has become routine for me [0.829] and I will continue to use mobile apps [0.754]. A not unreasonable proposal would be that young elderly with this set of attitudes could be early movers on digital wellness services, but this needs to be tested with field work.

The pricing of mobile applications also gave a consistent combination (Cronbach alpha $=0.820$ ); the mobile applications that cost something have reasonable prices [0.700] and the mobile applications give good value relative to prices [0.700]; these attitudes are encouraging as we mostly found the notion that digital wellness services should be for free when working with this issue in the semi-structured workshops.

For the attitudes on wellness we found a number of consistent statements (Cronbach alpha $=0.845$ ): intellectual challenges are important for my wellbeing [0.504]; I get sufficient intellectual stimulation from my everyday life [0.656]; my physical health has been good compared to people around me [0.690]; my resistance to illness is good [0.700]; the amount of information I have to process in my daily life is suitable for me (not too much, not too little) [0.611]; I expect my physical health to remain good [0.531]. A not unreasonable proposal-again- would be that groups with these attitudes among the young elderly could be early movers for digital wellness services but we need to work out verifications in filed studies with user groups.

A final step is to use the Mann-Whitney $U$ test to search for differences between pairs of independent groups; we have experimented with dividing the material in two groups in terms of age, educational background, status (working vs. retired), income classes and routine vs. advanced use of mobile applications (and of course gender) to find out if we have significant differences. We found that there are significant differences in the following statements:

- My physical health has been good compared to people around me [gender, 0.007]

- My resistance to illness is good [gender, 0.006]

- It is easy for me to learn to use mobile apps [age, 0.032]

- Intellectual challenges are important for my wellbeing [age, 0.018]

- I have the necessary knowledge to use mobile apps [education, 0.036]

- Intellectual challenges are important for my wellbeing [education, 0.003]

- I have the necessary knowledge to use mobile apps [status, 0.003]

- It is easy for me to learn to use mobile apps [status, 0.037]

- I can use mobile apps without assistance [status, 0.006]

- I get sufficient intellectual stimulation from my everyday life [status, 0.012]

- Intellectual challenges are important for my wellbeing [status, 0.003]

- Mobile apps are useful in my daily life [apps, 0.001] 
- Using mobile apps helps me to carry out important tasks [apps, 0.013]

- It is easy for me to learn to use mobile apps [apps, 0.044]

- My physical health has been good compared to people around me [income, 0.002]

- My resistance to illness is good [income, 0.045]

- Intellectual challenges are important for my wellbeing [income, 0.025]

The insight gained from this test is both a confirmation of the results of the previous tests and what factors to work on when collecting user groups that will be useful for co-creation of digital wellness services. There are some tentative conclusions we can make from the work with the survey material from the Åland Islands if we want to find and build good user groups for the design, implementation and testing of digital wellness services for young elderly before we introduce and launch them for large groups of users.

The choice of wellness is motivated by the fact that wellness services will not be dependent on health or social care data that is strictly regulated in most EU countries, with country-wise differences, and with confidentiality and privacy limitations. If digital wellness services become interventions in the daily routines of young elderly they will support the forming of daily wellness routines. Over time-the building and adoption of new wellness routines will take time [26] this will have a measurable impact on the health and social care costs

Digital wellness services for the young elderly has the potential to become a disruptive intervention in the com-mon wisdom on how to tackle the problems with an ageing population: it will be a pro-active, preventive program, it will promote wellness routines and change daily routines, it will improve health scenarios for elderly people and reduce public health and social care costs.

Young elderly that are active with full- or part-time work, or with voluntary work, are also active with mobile applications and find them useful for the tasks they carry out. Young elderly closer to 60 than 75 are more used to mobile applications, have the necessary knowledge and find it easier to learn how to use them. Active young elderly find intellectual stimulation in their everyday life, they find it important, which is also the case with people with higher education. Regarding wellness, young elderly with higher income is more positive to the status of their physical health and their possibilities to resist illness. These observations make sense and are not in conflict with the literature. Nevertheless, we need to point out that they are not that general because the sample is not large and the Åland Islands is a region in Finland. We will work on getting the material to validate the findings with a larger sample from mainland Finland in the next study we are carrying out.

\section{Summary and Conclusions}

The young elderly 60-75 age group was first ignored by the developers of mobile technology and the designers of mobile services as not interesting and then by the people worrying about the ageing population as they did not realize the potential to prevent functional impairment among the elderly through intervention among the young elderly. We show how such an intervention could be designed and implemented through digital wellness services over an omnivore platform on smart mobile phones with back-end support from a cloud service platform. A research program -BeWell- is being run with groups of young elderly, supported by two large associations for elderly, to find and design proper digital wellness services.

The young elderly age group represents $18-23 \%$ of the population in most EU countries. It is a large segment of the population that according to recent statistical estimates will be about 97 million EU citizens by 2020. A majority of the young elderly is healthy, active and socially interactive and do not require much intervention or support from the health and social care systems; for a minority of the group, however, we could claim that health, activity and social interaction are not so good.

We have chosen to work with digital wellness services as they will not be dependent on health or social care data that is strictly regulated in most EU countries with confidentiality and privacy limitations.

We work to find answers to four research questions: (1) will young elderly be a relevant user group for digital wellness services, (2) do young elderly find wellness issues important, (3) can digital wellness services form wellness routines and what should be the service design, and (4) what environment can sustain wellness routines for the young elderly?

Digital business is opening markets for innovative solutions to digital services, business models and ecosystems. This is where digital wellness services for young elderly should/will be heading-aiming for winning (mobile) platforms, using innovative business models and creating ecosystems of companies with high levels of productivity and cost effective operations. Digital wellness services for the young elderly has the potential to become a disruptive 
intervention in the common wisdom on how to tackle the problems with an ageing population: it will be a pro-active, preventive program, it will promote wellness routines and change daily routines, it will improve health scenarios for elderly people and reduce public health and social care costs.

We found answers first for research question 4: the impact being formed by the ageing population will make it a necessity to build and sustain wellness routines; the digital business provides the tools and the environment for building sustainable digital wellness services, which will be a prerequisite for sustainable wellness routines for the young elderly.

There are some benefits in operating with wellness in a four dimensional construct when interacting with the young elderly: (i) intellectual wellness, (ii) physical wellness, (iii) social wellness, and (iv) emotional wellness, which mirror functional impairment dimensions. We have noted that for building physical wellness the absolutes (or extremes) are not always accepted but that there is some reasonable level of physical wellness, which does not require daily exhortations. It is reasoned that an overall wellness can be maximized by compensating some missing level of physical wellness with improved intellectual wellness, or with improved social wellness, or with improved emotional wellness or with any combination of these. It will of course be a challenge to find some good trade-off between the wellness dimensions, and then to create digital wellness services to support and sustain them.

A digital wellness services program for the young elderly can be expected to quickly get hundreds of users (in Finland, the BeWell program is backed up by two major associations of the elderly with a total membership of more than 100000 members), soon turning into thousands of users and then scaling up to tens or hundreds of thousands of users in a fairly short time. The technology infrastructure needs to be planned for very large groups of users; technology developers and providers clearly want the user groups to grow to millions of users in all EU countries.

Advanced analytics tools that will work in an environment of heterogeneous and not well structured data sources are needed to build data fusion with further extensions to information and knowledge fusion. The fusion is a key to meaningful summaries and follow-up reports on progress of wellness routines, which can be designed to offer the advice of a coach or a personal trainer for the wellness service user. The advice is a typical value-adding service that will drive commercial solutions for the digital wellness services.

The design of digital wellness services and the work with the supporting technology produced answers to research question 3: The design of digital wellness services should be done with the users, not for the users; the ADR offers a reasonable basis for interactive design work with the young elderly; the technology framework should provide data, information and knowledge as support for the adoption of wellness services; the user interface should be an omnivore platform to allow users to compose services that can sustain wellness routines

The empirical study that we carried out collected material from 101 young elderly respondents that gave some good guidelines on how to select members in user groups to be organized for the design, implementation and testing of digital wellness services for young elderly.

The statistical analysis of empirical material gave us answers to research question 2: Young elderly rate the wellness issues as important; by combining the wellness proposals with the proficiency of using mobile apps we find support for the plan to build digital wellness services for mobile (omnivore) platforms. We also found answers to research for it to be a viable proposal to promote digital wellness services as an intervention to build wellness routines.

\section{References}

[1] T.B. Adams, The Power of Perceptions: Measuring Wellness in a Globally Acceptable, Philosophically Consistent Way. Hershey, PA: Wellness Management, 2003.

[2] H. Bouwman, C. Carlsson and P. Walden, Mobile R\&D prototypes - What is hampering market implementation, International Journal of Innovation and Technology Management, vol.11, no.1, pp. 18, 2014.

[3] H. Bouwman, C. Carlsson, M. de Reuwer, and M. Warnier, Mobile cloud computing: state of the art and outlook, info, vol 15, no 1, pp. 4-16, 2013.

[4] H. Bouwman, H. Vos and T. Haaker, Mobile Service Innovation and Business Models. Berlin-Heidelberg: Springer, 2008.

[5] C. Carlsson and P. Walden, Digital wellness for young elderly: research methodology and technology adaptation, in Proceedings of 28th Bled eConference, Bled, Slovenia, 2015, pp. 239-250.

[6] C. Carlsson, Soft computing in analytics: handling imprecision and uncertainty in strategic decisions, Fuzzy Economic Review, vol. XVII, no. 2, pp. 3-21, 2012.

[7] C. Carlsson and P. Walden, From MCOM visions to mobile value services in The First 25 Years of the Bled eConference (R. Clarke, A. Puchar and J. Gricar, Eds.). Maribor: University of Maribor, Faculty of Organizational Sciences, 2012, pp. 69-91.

[8] D. Chaffey, Digital Business and E-Commerce Management. Harlow: Pearson, 2015. 
[9] Functional Impairment. (2009, June) What is functional impairment? Disentangling disability from clinical significance. World Psychiatry. [Online]. Available: http://www.ncbi.nlm.nih.gov/pmc/articles/PMC2691163/

[10] C. Gronroos, Service logic revisited: who creates value? And who co-creates?, European Business Review, vol. 20 no. 4, pp. 298-314, 2008.

[11] S. Gurtner, R. Reinhardt and K. Soyez, Designing mobile business applications for different age groups, Technological Forecasting and Social Change, vol. 88, pp.177-188, 2014.

[12] I. Hardilland and C.W. Olphert, Staying connected: exploring mobile phone use amongst older adults in the UK, Geoforum, vol. 43, pp. 1306-1312, 2012.

[13] A.R. Herzog, J.S. House and J.N. Morgan, Relation of work and retirement to health and well-being in older age, Psychology and Aging, vol. 6, no.2, pp. 202-211, 1991.

[14] J. Ludbrook, Analysis of $2 \times 2$ tables of frequencies: Matching test to experimental design, International Journal of Epidemiology, vol. 37, no. 6, pp. $1430-1435,2008$.

[15] C. R. Mehta and P. Senchaudhur. (2003, September) Conditional versus unconditional exact tests for comparing two binomials. Nbi. [Online]. Available: http://www.nbi.dk/ petersen/Teaching/Stat2009/Barnard ExactTest TwoBinomials.pdf

[16] J.E. Myers, T.J. Sweeney and M. Witmer. (2014, December) A holistic model of wellness. Mind-Garden. [Online]. Available: http://www.mind-garden.com/products/wells.htm

[17] F. Nikayin, M. de Reuver and T. Itälä, Collective action for a common service platform for independent living services, International Journal of Medical Informatics, vol. 82, no. 10, pp.922-939, 2013.

[18] J.N. Rachele, T.L. Washington, T. F. Cuddihy, F.A. Barwais, and S.M. McPhail, Valid and reliable assessment of wellness among adolescents: Do you know what you are measuring? International Journal of Wellbeing, vol. 3, no. 2, pp. 162-172, 2013.

[19] R. Saracci. (1997, May) The world health organization needs to reconsider its definition of health. BMJ. [Online] Available: http://www.bmj.com/content/314/7091/1409

[20] M.K. Sein, O. Henfridsson, P. Sandeep, M. Ross,i and R. Lindgren, Action design research, MIS Quarterly, vol. 35, no.1, pp. 37-56, 2011.

[21] A. Sell, P. Walden and C. Carlsson, Segmentation matters: an exploratory study of mobile service users, International Journal of Systems and Service Engineering, vol. 2, no. 3, pp. 1-17, 2011.

[22] A. Sell, P. Walden and C. Carlsson, I am a smart phone user - key insights from the Finnish market, in Proceedings of the ICMB 2012, TU Delft, Delft, 2012, pp. 265-276.

[23] Statistics Finland. (2014, September) Uusimmat Tilastotiedot. Tilastokeskus. [Online]. Available: http://www.stat.fi

[24] Student Health and Counselling Services. (2015, June) Student Wellness Survey. UC: Davis: [Online]. Available: https:// shcs.ucdavis.edu/wellness/

[25] United Nations Department of Economic and Social Affairs. (2014, August) Population ageing and sustainable development. Population Facts. [Online]. Available: http://www.un.org/en/development/desa/population/ publications/pdf/popfacts/PopFacts 2014-4.pdf

[26] V. Venkatesh, J.Y.L. Thong and X. Xu, Consumer acceptance and use of information technology: Extending the unified theory of acceptance and use of technology, MIS Quarterly, vol. 36, no.1, pp. 157-178, 2012.

[27] World Health Organization. (2014, August) Preamble to the constitution. WHO. [Online]. Available: http://www.who.int

[28] N. Xie, W. Wang, B. Ma, X. Zhang, W. Sun and F. Guo, Research on an agricultural knowledge fusion method for big data, Data Science Journal, vol.14, no. 7, pp. 1-9, 2015

[29] R. Zuech, T.M. Khoshgoftaar and R. Wald, Intrusion detection and big heterogeneous data: a survey, Journal of Big Data, vol. 2, no. 3, pp 3-41, 2015.

[30] Wellness Proposal. (2016, June) Definition of wellness. Wellness Proposal. [Online]. Available: http://wellnessproposals.com/wellness-articles/definition-of-wellness/ 